\title{
7. DIGITAL FUTUREcongress in Frankfurt
}

Am 14.02.2019 (Valentinstag) startet in Frankfurt der 7. DIGITAL FUTUREcongress. Entscheider haben dort die Möglichkeit, an einem Tag alle ihre Themen auf der eigenen Digitalisierungsagenda mit Experten zu besprechen und Lösungen mit nach Hause zu nehmen. Mehr als 3300 Teilnehmer waren am 1. März in die MesseFrankfurt gekommen, um am 6. DIGITAL FUTUREcongress im Forum teilzunehmen. Bei dieser Kongressmesse, die weniger die technischen Aspekte als vielmehr die Wahl der richtigen Strategie und das Verständnis für die Thematik und praktikable Lösungen für Unternehmen in den Vordergrund stellt, präsentierten insgesamt knapp 150 Aussteller ihre Angebote für die Digitalisierun.

150 Aussteller, 50 Speaker, Podiumsdiskussion, Keynotes, Workshops und eine optimale Plattform, um sich über BestPractices und neue Digitalisierungsstrategien auszutauschen - das erwartet die Besucher des DIGITAL FUTUREcongress in Frankfurt. So können sich Besucher und Aussteller im direkten Kontakt über innovative IT-Themen unterhalten, gemeinsam neue Ideen entwickeln und die optimale Lösung für ihr Unternehmen finden. Der Kongress ist in vier Themenbereiche aufgeteilt:
1. Online-Marketing und Vertrieb

2. Prozessoptimierung und IT-Infrastruktur,

3. Arbeit 4.0 - Neue Arbeitswelten HR, Future-Thinking

4. Cyber-Security und Datenschutz

5. Management und Transformation

Weitere Informationen unter: https://frankfurt.digital-futurecongress.de/

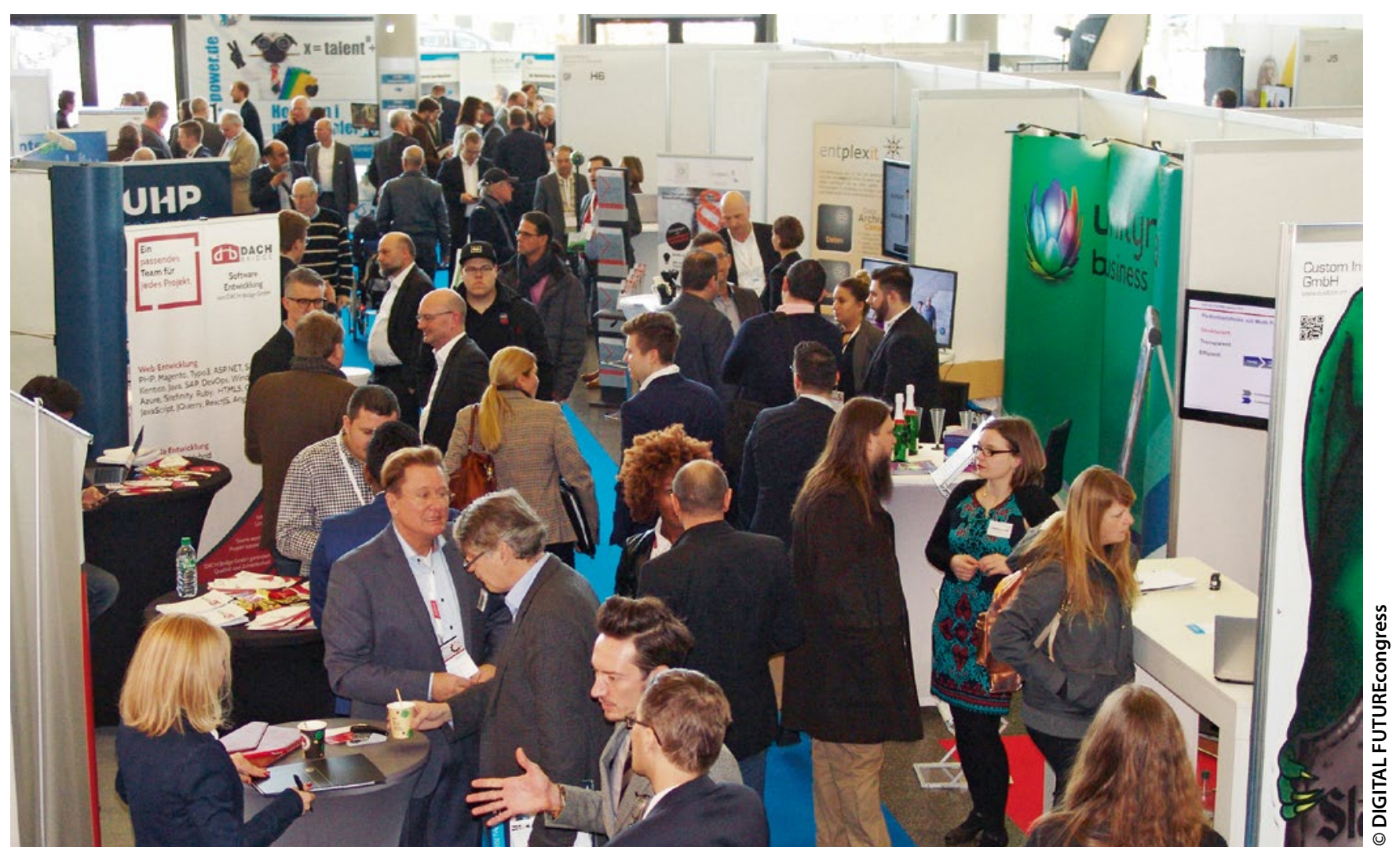

Reges Treiben auf dem DIGITAL FUTUREcongress in Frankfurt am Main. 